\title{
UMA ANÁLISE CRÍTICA DO INTERNET.ORG COMO UMA PRÁTICA DE DIFUSÃO DE ACESSO À REDE MUNDIAL DE COMPUTADORES
}

\section{A CRITICAL ANALYSIS OF INTERNET.ORG AS AN PRACTICE OF SPREAD THE WORLD WIDE WEB}

\author{
${ }^{1}$ Daniel Evangelista Vasconcelos Almeida \\ 2Juliana Evangelista de Almeida
}

\section{RESUMO}

A Internet é cada vez mais acessada pelos usuários, podendo ser considerado como um bem essencial. Entretanto, o acesso não é disponível a todos, sendo necessário que se difunda tal bem ante a possibilidade de se considerar um direito fundamental. O Facebook mantém um projeto intitulado de Internet.Org que pretende a difusão do acesso à Internet a todos cantos do mundo e a todas as camadas sociais. A presente pesquisa visa investigar se o acesso à Internet pode ser considerado um direito fundamental e se o projeto feito pelo Facebook pode ser considerado uma prática de difusão desse direito.

Palavras-chave: Internet.org, Acesso à internet como direito fundamental, Internet como um bem essencial

\begin{abstract}
The Internet is increasingly accessed by users and can be considered as an essential good. However, the access is not available to everyone and it is necessary spread this good in view of the possibility to consider the access as a fundamental right. The Facebook keeps a project titled Internet.Org which wants to spread the Internet access to all corners of the world and all stratum. This research aims to investigate if the access to the Internet can be considered a fundamental right and if the project done by Facebook can be considered a practice of dissemination of this right.
\end{abstract}

Keywords: Internet.org, Internet access as a fundamental right, Internet as an essential good

\footnotetext{
${ }^{1}$ Mestrando em Direito Privado pela Pontifícia Universidade Católica - PUC, Belo Horizonte, Minas Gerais, (Brasil). Advogado do Almeida e Almeida - Advogados Associados, AEA, Brasil. E-mial: danielevangelista@gmail.com ${ }^{2}$ Doutoranda em Direito Privado pela Pontifícia Universidade Católica - PUC, Belo Horizonte, Minas Gerais,Brasil. Professora de Direito Civil na FACHI/FUNCESI e na Nova Faculdade - NF, Contagem, Minas Gerais, Brasil. E-mail: jualmeidaonline@gmail.com
} 


\section{INTRODUÇÃO}

A Internet está cada vez mais presente no mundo moderno. Os smartphones cada vez mais acessíveis e inteligentes. A velocidade de acesso aumenta de forma exponencial. Um usuário, atualmente, posta fotos no Instagram, comenta posts no Facebook, expõe sua opinião no Twitter, troca mensagens no WhatsApp, Telegram, Viber e Skype, utiliza plataformas para o entretenimento, como o SnapChat, se vale do Google Maps ou Waze para transitar nas cidades. É possível inclusive realizar transações bancárias por meio de aplicativos. É inegável que o acesso à rede se mostra necessário.

Neste sentido, a Internet é muito mais que um facilitador para as interações sociais, podendo inclusive ser considerado um bem essencial. Para isso, faça uma projeção de sua vida sem as ferramentas disponíveis online e veja o quão depende delas está. Mais além, a Internet pode ser uma ferramenta para a difusão de cultura e conhecimento, tendo em vista a vasta quantidade de informação nela inseridas, não só obras em domínio público, mas também obras previamente licenciadas para o uso.

Conquanto a disponibilidade pareça ser universal, uma pesquisa feita pela ONU mostrou que nos 48 países mais pobres do mundo $90 \%$ da população não possui acesso à Internet (REUTERS, 2016). Visando ampliar o acesso à rede, o Facebook desenvolve um projeto intitulado de Internet.Org, o qual tem a missão de levar a Internet para todos.

Referido projeto possibilita o acesso gratuito à uma plataforma do Facebook, no qual o usuário terá acesso à rede social e também ao conteúdo dos parceiros que apoiarem financeiramente o projeto. Por mais que essa prática possa ferir a neutralidade da rede esse não será o foco deste artigo.

$\mathrm{O}$ presente artigo visa explicar o direito de acesso à Internet como um direito fundamental e analisar se o projeto Internet.Org pode ser considerado uma prática de universalização do acesso à Internet, o qual é uma das 10 diretrizes da ONU para a Internet. Assim, o cerne não será a neutralidade da rede, mas sim o direito de acesso.

Para tal, no capítulo 2 será evidenciado como a Internet contribui para a disseminação de cultura e conhecimento. Será mostrado o <www.dominiopublico.gov.br> que é uma plataforma mantida pelo governo brasileiro para a disponibilização de obras que estão em domínio público, bem como o creative commons, que se trata de uma licença prévia de direitos autorais.

No capítulo 3 será trabalhado a ideia da Internet como um bem fundamental e o direito de acesso como um direito fundamental. Nesse sentido, será conceituado o que se entende por 
direitos fundamentais, tecendo explicações sobre tal instituto. Ademais, será apresentada as diretrizes da ONU para a Internet, focando no princípio do acesso.

Por fim, no capítulo 4 será apresentado o Internet.Org, tendo em vista que ele pode ser considerado uma prática de difusão de acesso à rede. Será feita uma análise do projeto à luz do ordenamento jurídico brasileiro, tendo em vista o Marco Civil da Internet.

\title{
2 A DISSEMINAÇÃO DE CULTURA PELA INTERNET
}

Pierre Levy (1999) inicia sua obra Cibercultura dizendo que:

\begin{abstract}
Pensar a cibercultura: esta é a proposta deste livro. Em geral me consideram um otimista. Estão certos. Meu otimismo, contudo não promete que a Internet resolverá, em um passe de mágica, todos os problemas culturais e sociais do planeta. Consiste apenas em reconhecer dois fatos. Em primeiro lugar, que o crescimento do ciberespaço resulta de um movimento internacional de jovens ávidos para experimentar, coletivamente, formas de comunicação diferentes daquelas que as mídias clássicas nos propõem. Em segundo lugar, que estamos vivendo a abertura de um novo espaço de comunicação, e cabe apenas a nós explorar as potencialidades mais positivas deste espeço nos planos econômico, político, cultural e humano. (LEVY, 1999, p. 11)
\end{abstract}

Pierre Levy é um filósofo que em sua obra fez um estudo das revoluções que o mundo digital trouxe para a sociedade, analisando os futuros desafios a serem enfrentados. Da compreensão de sua obra percebe-se que o mundo não é mais o mesmo e que conquanto existam desafios e paradigmas as serem quebrados, as tecnologias tem o condão de estabelecer mudanças positivas nos planos econômicos, político e principalmente cultural.

Com a informatização das produções humanas é possível se universalizar o saber, deixando com que esse não seja mais concentrado. Isso porque "Quanto mais o digital se afirma como um suporte privilegiado de comunicação e colaboração, mais essa tendência à universalização marca a história da informática." (LEVY, 1999, p. 112).

Esse é o papel fundamental que a rede mundial de computadores deve realizar, qual seja, universalizar o acesso ao conhecimento. Esse que como fruto da criação do homem é protegido pelo instituto da propriedade intelectual. Sabe-se que a Propriedade Intelectual é gênero, da qual se tem as espécies Propriedade Industrial e Direitos Autorais.

De uma maneira geral, o microssistema da Propriedade Intelectual visa a proteção daquele acervo imaterial, seja da pessoa natural ou não natural, haja vista que a pessoa jurídica pode ser titular de Direitos sobre obras, ainda que de forma derivada (POLI, 2008). A grosso modo, os Direitos Autorais são a proteção dada as obras criadas por pessoas naturais, enquanto 
que a Propriedade Industrial é a proteção dada aos acervos empresariais. Neste aspecto, é evidente que a cultura e o conhecimento em si são protegidos pelo Direito Autoral, tendo em vista que músicas, fotos, vídeos, textos e outras obras serão protegidas por tal instituto. Conforme Bittar (2003), o Direito Autoral é a espécie de Propriedade Intelectual que tutela a proteção da criação e da utilização de obras intelectuais estéticas, seja na literatura, artes ou ciência.

Assim, o que a Internet realiza é uma mudança na análise do instituto do Direito Autoral. É evidente que houve uma mudança no suporte fático que a obra é exteriorizada. Observe que um livro pode não ser impresso em papel, mas ser exteriorizado através de um e-book, uma música pode ser compartilhada em serviços de streaming e assim em diante. Nesse aspecto, é preciso que se questione a universalidade do acesso, o que é defendido inclusive por Lawrence Lessig (2005) em seu livro Cultura Livre. O que o autor defende converge com o pensamento de Pierre Levy (1999), ao passo que ele afirma que o conhecimento e a cultura são a finalidade última da rede mundial de computadores, ou seja, o valor da universalidade deve ser a máxima da cibercultura. Nas palavras de Pierre Levy:

\begin{abstract}
Por outro lado, o significado último da rede ou o valor contido na cibercultura é precisamente a universalidade. Essa mídia tende à interconexão geral das informações, da máquina e dos homens. E portanto se, como afirmava McLuhan, 'a mídia é a mensagem', a mensagem dessa mídia é o universal, ou a sistematicidade transparente e ilimitada. Acrescentemos que esse traço corresponde efetivamente aos projetos de seus criadores e às expectativas de seus usuários (LEVY, 1999, p. 113)
\end{abstract}

Nesse aspecto é necessário que se questione a atual forma de proteção dos Direitos Autorais, tendo em vista que as novas tecnologias mudaram a forma de interpretação das criações. É preciso se compatibilizar a Lei de Direitos Autorais com os anseios da sociedade (VIEGAS; POLI, 2014).

Condição da pessoa humana é a criatividade. Externa-se ao mundo grande parte do pensamento e este, dada a sua relevância, merece proteção jurídica. Assim, pode-se compreender a Propriedade Intelectual como o conjunto de bens imateriais oriundos da criatividade humana que foram externados de alguma forma. Perceba que a Propriedade Intelectual não é a materialidade em si, mas o ato criativo, ou ainda, a criatividade por traz da materialização. Ainda, a Propriedade Intelectual se trata de direito fundamental, inserto no artigo $5^{\circ}$ da Constituição da República Federativa do Brasil de 1988 (BRASIL, 1988), incisos XXVII, XXVIII e XXIX, gozando, pois, de proteção. 
Essa proteção comporta em direitos de exigir obrigações positivas e negativas contra terceiros, como por exemplo o direito de remuneração e o direito de ter seu nome vinculado à obra. O Direito Autoral se divide em direitos morais do autor e direitos patrimoniais do Autor. O Primeiro é um direito personalíssimo e como tal não se extingue com o decurso do tempo. Por sua vez, o direito patrimonial não é eterno, ou seja, o direito à exclusividade da obra, por assim dizer o direito de receber unicamente pela reprodução desta tem fim, conquanto o direito moral de paternidade não. Tratando-se de Direito Autoral, o direito de explorar economicamente uma obra expira em 70 anos contados a partir de $1^{\circ}$ de janeiro do ano subsequente à morte do autor ou à publicação sendo este anônimo ou pseudônimo (BRASIL, 1998).

Daí é que se questiona a plausibilidade deste prazo de proteção, tendo em vista que hoje as interações são cada vez mais velozes, poder-se-ia discutir se tal prazo não é demasiadamente longo.

Em contraponto com os Direitos Autorais existem formas de licenciamento prévio de uso, uma alternativa à difusão de cultura. Destaca-se o Creative Commons, que é uma forma de licenciamento prévio, estabelecida, com diversas possiblidades de combinação para que se possibilite o uso em determinadas circunstâncias já escolhidas pelo Autor. No mesmo sentido é a adoção do software livre. Software livre, como o próprio nome indica, é aquele livre de quaisquer amarras, sendo garantido ao menos a liberdade de usar o programa como se quiser. Em verdade, o movimento do Software livre é antigo e não significa gratuidade. O que se quer dizer é que um software pode ser livre e não gratuito, ou gratuito e não livre, pois são conceitos distintos.

Perceba que o interesse em alternativas aos Direitos Autorais é a disseminação do conhecimento e da cultura. Em verdade, após o prazo de proteção de qualquer obra ela entra em domínio público, ou seja, pode ser utilizada sem a remuneração do autor da obra, em que pese preservados os direitos morais deste. Neste sentido, o governo brasileiro mantém um portal no qual são disponibilizadas obras em domínio público, qual seja, o <www.dominiopublico.org.br>.

O "Portal Domínio Público", lançado em novembro de 2004 (com um acervo inicial de 500 obras), propõe o compartilhamento de conhecimentos de forma equânime, colocando à disposição de todos os usuários da rede mundial de computadores Internet - uma biblioteca virtual que deverá se constituir em referência para professores, alunos, pesquisadores e para a população em geral. (DOMÍNIO, 2016) 
Trata-se de uma clara tentativa de disseminação de cultura, informação e conhecimento. No portal são disponibilizados diversos livros, músicas, vídeos que não são mais protegidos patrimonialmente pela Lei de Direitos Autorais. Projetos como esse servem como um exemplo de que a Internet é uma inegável fonte de conhecimento e um instrumento de disseminação de cultura.

\section{A INTERNET COMO DIREITO FUNDAMENTAL}

A sociedade experimenta cada vez mais um mundo digital. Diversas são as interações que ocorrem na rede mundial de computadores. Entretanto, ainda se trata de um fenômeno relativamente recente que carece de atenção. O acesso à Internet se mostra uma necessidade do homem moderno. Nesse sentido, questiona-se a possibilidade de o acesso à Internet ser considerado um direito fundamental.

De início, é preciso que se distinga os "direitos do homem", "direitos humanos" e os "direitos fundamentais". Não é uma tarefa simples estabelecer um conceito bem definido para estes termos, sendo que muitos autores trabalham com as expressões direitos fundamentais e direitos humanos como sinônimas (FERNANDES, 2014).

Seguindo a doutrina de Bernardo Fernandes (2014), é possível definir os direitos do homem no sentido de direitos naturais, ou seja, não positivados ou ainda não positivados; direitos humanos positivados na esfera do direito internacional; e os direitos fundamentais protegidos e positivados dentro de cada Estado.

Tais direitos surgem da necessidade de proteção do ser humano, tanto em face do Estado como em face de outros, o que se denomina, respectivamente, de eficácia vertical e eficácia horizontal dos direitos fundamentais. Perceba que se trata de uma construção voltada para a proteção do ser humano. Nas palavras de Bernardo Fernandes:

[...] falar em direitos fundamentais é falar em condições para a construção e o exercício de todos os demais direitos previstos no Ordenamento Jurídico (interno), e não apenas em uma leitura reducionista, como direitos oponíveis contra o estado. (FERNANDES, 2014, p. 308)

Pode-se classificar os direitos fundamentais em gerações, isso de acordo com a evolução temporal e histórica da humanidade. A doutrina é pacífica em classificar os direitos fundamentais em três gerações, sendo que essa é inclusive a classificação feita pelo Supremo 
Tribunal Federal. Entretanto, há doutrinadores que dividem em quatro ou até mesmo em cinco gerações.

A primeira geração dos direitos fundamentais pode ser entendida como a afirmação dos direitos de liberdade. Surgiu no final do século XVIII e início do século XIX. O contexto era das Revoluções Burguesas, a qual tinha como ideal a liberdade. O que se pregava era a afirmação das liberdades individuais face ao Estado. Assim, na primeira geração de direitos fundamentais estão os direitos civis e políticos, esculpidos sob a forma de liberdade.

Já no século XX, surge os direitos fundamentais de segunda geração. Conforme Fernandes (2014), são eles os direitos sociais, culturais e econômicos. Tal geração é fruto da revolução industrial, a qual ocasionou diversos problemas sociais. $\mathrm{Na}$ época, era necessário a afirmação de uma série de Direitos, tendo em vista as péssimas condições de trabalho e a necessidade de o Estado garantir a dignidade daqueles trabalhadores. Nesse momento histórico se percebeu que os direitos fundamentais não são só uma proteção do indivíduo em face do Estado, mas também como sendo uma garantia institucional de Igualdade.

Já no final do século XX, no contexto pós-guerra, veio a terceira geração de direitos fundamentais. $\mathrm{O}$ fundamento seria o princípio da fraternidade, que diz respeito ao "direito ao desenvolvimento, direito à paz, direito ao meio ambiente, direito de comunicação" (FERNANDES, 2014, p. 312). Isso é reflexo do processo acelerado de globalização.

Referido processo, conforme leciona Bonavides (2016), ocasionou uma exigência de universalização dos direitos fundamentais. Como as barreiras geográficas no mundo moderno foram diminuindo, surgiu a necessidade de formação de uma sociedade aberta. Assim, o autor reconhece os direitos fundamentais da quarta geração, como sendo o direito à democracia, à informação e ao pluralismo. Fernandes (2014), leciona que há autores que defendem que o direito contra manipulações genéticas, à mudança de sexo e os direitos relacionados à biotecnologia também fazem parte da quarta geração, são eles José Alcebíades Oliveira Júnior e Dirley da Cunha Junior.

Indo além dessa geração, há quem defenda a existência da quinta geração dos direitos fundamentais. Bonavides (2016) vislumbra a paz como um direito de quinta geração, ao argumento de que há a necessidade de universalização deste direito. No mesmo sentido, Fernandes (2014) afirma que os direitos da quinta geração tem uma relação intrínseca com o direito à vida "[...] sob os desafios das novas tecnologias, derivando então um direito à identidade individual, ao patrimônio genético e à proteção contra o abuso de técnicas de clonagem." (FERNANDES, 2014, p. 314). 


\title{
3.1 Diretrizes da ONU Sobre a Internet
}

O ordenamento jurídico não é composto meramente por leis. São fontes do Direito a lei, os usos e costumes, a jurisprudência, a doutrina e os princípios gerais do Direito. A Internet é um fenômeno transnacional. Não possui barreiras físicas. Entretanto, não é o fato de que não há uma estrutura física que implica na ausência de normas; do mesmo modo que não há que se falar que em virtude da universalidade da Internet não existem normas que regulem as atividades e fatos que nela ocorrem.

Tendo como diretriz o ordenamento jurídico brasileiro, pode-se afirmar que a Internet não é um local em que se pode cometer abusos, até porque o ato ilícito e o abuso de direito são ilícitos civis, conforme artigos 186, 187 e 927 do Código Civil (BRASIL, 2002). Ademais, o Brasil é considerado pioneiro ao promulgar uma legislação sobre a Internet, o Marco Civil - lei 12.965 de 2014 (BRASIL, 2014). Destarte, ante ao fato de nas relações digitais tudo se alterar com muita velocidade, a atividade legislativa não consegue refletir a ordem social vigente, o que acarreta em normas sem efetividade. Por isso afirma-se que prevalecem os princípios em relação às regras.

\begin{abstract}
No Direito Digital prevalecem os princípios em relação às regras, pois o ritmo de evolução tecnológica será sempre mais veloz que o da atividade legislativa. Por isso, a disciplina jurídica tende à autorregulamentação, pela qual o conjunto de regras é criado pelos próprios participantes diretos do assunto em questão com soluções práticas que atendem ao dinamismo que as relações de Direito Digital exigem. (PINHEIRO, 2010, Pg. 72)
\end{abstract}

Assim sendo, em uma visão holística do fenômeno da Internet, existe a necessidade de se estabelecer princípios para o melhor convívio entre os usuários. Com esta premissa, a ONU (Organização das Nações Unidas), em 30 de Marco de 2011, lançou uma instrução que define os princípios e direitos que formam o alicerce da governança dentro da internet (DIREITOS, 2016).

Há que se ressaltar a legitimidade que a ONU possui para definir regras de conduta. Sabe-se que a ONU é uma governança, pois tem o poder de influência em todos os países que ratificaram seu tratado, se submetendo a esta. Conforme Rosenau e Czempiel:

\footnotetext{
“[...] governança é um fenômeno mais amplo que governo; abrange as instituições governamentais, mas implica também mecanismos informais, de caráter nãogovernamental, que fazem com que as pessoas e as organizações dentro da sua área de atuação tenham uma conduta determinada, satisfaçam suas necessidades e respondam às suas demandas". (ROSENAU; CZEMPIEL, 2000, pg. 15/16)
} 
Em verdade, a instrução supracitada definiu dez princípios, quais sejam, 1 Universalidade e Igualdade, 2 - Direitos e Justiça Social, 3 - Acessibilidade, 4 - Expressão e Associação, 5 - Privacidade e Proteção de Dados, 6 - A Vida, Liberdade e Segurança, 7 Diversidade, 8 - Rede de Igualdades, 9 - Normas e Regulamentos, 10 - Governança.

Os princípios tratam-se de um reflexo da Declaração Universal dos Direitos dos Homens de 1948. Assim, todos os indivíduos têm o direito a proteção na Internet, devendo ser tratados de maneira igualitária, devendo ser protegidos em âmbito digital o que consubstancia o princípio da Universalidade e Igualdade.

O princípio do Direito e Justiça Social define que a Internet é um espaço em que se deve respeitar os direitos humanos. Até mesmo porque essa é a maior preocupação da ONU, o de respeito ao homem. Infelizmente são comuns as práticas racistas e xenofóbicas na Internet, assim o que quer a ONU é proteger todos os usuários da internet.

Quanto aos princípios da Expressão e Associação, Privacidade e Proteção de Dados e a Vida, Liberdade e Segurança, há que se fazer uma análise conjunta. Em suma o primeiro garante a liberdade de informação, o segundo a privacidade dos indivíduos e o terceiro a segurança na Internet.

O princípio da Diversidade trata-se de uma garantia as diversas manifestações que podem ocorrer na Internet. Já o princípio das Normas e Regulamentos prevê que a Internet operará em uma linguagem de sistemas única, permitindo que todos os usuários tenham a possibilidade de acesso a qualquer conteúdo.

Um princípio que veementemente não é cumprido é o da Acessibilidade, juntamente com o princípio da Rede de Igualdades, segundo os quais todos os indivíduos tem direito ao acesso à Internet aberta. Conquanto a maioria dos países desenvolvidos possui um amplo e consistente acesso à rede mundial de computadores, países subdesenvolvidos não contam com o mesmo privilégio. Afirma-se que mais da metade da população mundial não tem acesso à Internet (REUTERS, 2016).

O que se depreende da análise dos princípios supracitados é que estes são um reflexo da Declaração Universal dos Direitos do Homem de 1948. Ainda, ressalta-se que o que se intenta com tais princípios é se regular as relações digitais, bem como se buscar a efetividade da dignidade da pessoa humana. Entretanto, o acesso à Internet pode ser visto como um direito fundamental, garantindo aos indivíduos uma inclusão na sociedade, tendo em vista que cada vez mais as relações sociais têm se tornado digitais.

Conquanto não esteja positivado expressamente na Constituição, é possível que se interprete o Direito de Acesso como sendo um direito fundamental. Isso porque o artigo $5^{\mathrm{a}}$ não 
traz um rol taxativo. Ademais, os tratados de direitos humanos constituem verdadeiros direitos fundamentais conforme o $§ 2^{\circ}$ do Artigo $5^{\circ}$ da Constituição ${ }^{1}$ (BRASIL, 1988). É inegável que o direito ao acesso é garantido pelo Marco Civil (BRASIL, 2014). Entretanto, para ser considerado um direito fundamental será necessária uma melhor interpretação, tendo em vista que ele não é expresso. Nesse sentido, afirma-se que o Direito de Acesso é um direito fundamental por uma interpretação teleológica da Constituição e em conjunto com as diretrizes da ONU, nas quais é expresso que "este documento define dez direitos fundamentais e princípios base de governança da Internet” (DIREITOS, 2016).

\subsection{O princípio da Acessibilidade e sua Influência na Sociedade}

Como visto, o princípio da acessibilidade diz respeito ao direito de acesso à internet. Isso decorre do fato de que hoje o mundo "está" digital. Ora, transações bancárias, reuniões, investimentos em valores mobiliários dentre outras práticas profissionais podem ser feitas por meio da Internet. Ainda, no âmbito pessoal, é inegável a quebra de paradigma que a rede trouxe, tendo em vista que se pode manter um contato ativo com uma pessoa que não se convive fisicamente, isso através das redes sociais.

Ivan Hartmann (apud GOULART, 2016) sustenta a ideia de que há um direito fundamental de acesso à internet. $\mathrm{O}$ argumento é de que a Constituição, no que se refere aos direitos fundamentais, não é uma norma fechada, mas que contempla aspectos não elencados em seu rol, tal qual o direito ao acesso à internet.

A grande questão é que a Internet pode e deve ser vista como um instrumento de inserção em sociedade. Não estar em meio digital hoje pode significar uma exclusão de diversas interações sociais. Isso reflete na desenvoltura econômica da sociedade.

Enquanto nos países desenvolvidos o acesso à Internet está próximo de ser saturado, nos 48 países mais pobres do mundo $90 \%$ da população não possui acesso à Internet (REUTERS, 2016). Estar fora desta rede é não se inteirar da evolução da sociedade como um todo.

Observe que a gama de informação a que os usuários são expostos é uma amostra de que o viver digital é importante, podendo até mesmo ser considerado essencial. (CORTE ALEM Ã, 2015)

\footnotetext{
1 Art. $5^{\circ}$ Todos são iguais perante a lei, sem distinção de qualquer natureza, garantindo-se aos brasileiros e aos estrangeiros residentes no País a inviolabilidade do direito à vida, à liberdade, à igualdade, à segurança e à propriedade, nos termos seguintes:

$\S 2^{\circ}$ Os direitos e garantias expressos nesta Constituição não excluem outros decorrentes do regime e dos princípios por ela adotados, ou dos tratados internacionais em que a República Federativa do Brasil seja parte.
}

Revista de Direito, Goverrnaça e Novas Tecnologias | e-ISSN: 2526-0049| Brasília | v. 2 | n. 1 | p. 148 - 166 | Jan/Jun. 2016. 
Ademais, a Internet é fonte inegável de conhecimento. Além do já explicitado "www.domíniopublico.org", que é um site brasileiro para a divulgação de obras não mais protegidas patrimonialmente pela Lei de Direitos Autorais brasileira, diversas são as fontes de informação na rede.

É necessário destacar que muitas das vezes o empecilho para a difusão da Internet não é nem econômico nem político, muitas das vezes pode se dar em razão do idioma utilizado. Conforme pesquisa da ONU, apenas cerca de 5\% das 7.100 línguas do mundo estão representadas na Internet (REUTERS, 2016).

Nesse sentido, a estrutura da Internet, por utilizar o alfabeto latino, acaba por excluir usuários que não entendem tal linguagem. É evidente que o uso do alfabeto latino se restringe aos nomes de domínio, podendo outros idiomas serem utilizados nas páginas. Há aqueles usuários que desconhecem totalmente as letras utilizadas, por não terem contato com o alfabeto latino. Não se quer afirmar que exista a necessidade de adequação do sistema de nomes de domínio para que comporte também as línguas que não utilizam o alfabeto latino, mas há que se questionar a colaboração que esse fato dá para a extinção de diversos idiomas, os quais são pouco utilizados.

A atual geração da sociedade enfrentará o desafio de conviver cada vez mais conectada. É um caminho sem volta. O próximo passo será a Internet das Coisas ${ }^{2}$. Imagine um mundo onde tudo é conectado? Neste mundo aquele indivíduo que não tiver acesso à Internet será, de certo, excluído do convívio social. Esses desafios serão cada vez mais frequentes. Perceba que se caminha cada vez mais para um mundo digital. Cada vez mais a tecnologia se desenvolve e se inserem mais práticas em meio digital, o que gera a necessidade de se garantir a inserção de todos os indivíduos nas relações digitais.

É evidente que o acesso à Internet deve ser visto como um direito fundamental de todo cidadão. Fazer parte dela não é uma questão de hobby ou de autoafirmação em redes sociais, mas sim uma questão precipuamente social. Ora, estando fora da rede, um indivíduo pode ser privado de diversas interações sociais. Como compatibilizar a necessidade de um mundo global com um a ausência de disseminação de informação.

O indivíduo necessita da Internet, entretanto há que se questionar como esse acesso é oportunizado. É preciso que se tenha um acesso livre e desimpedido de qualquer censura, o que não é feito em alguns países de governo totalitário. Isso é mais uma evidência de que o acesso

\footnotetext{
${ }^{2}$ Internet das Coisas é um avanço da tecnologia. Nela tudo estará conectado. Carros, casas, geladeiras, e outros bens serão conectados à rede, facilitando a vida dos usuários, tendo em vista a automatização de tarefas cotidianas.
} 
à Internet é necessário, tendo em vista que os governos totalitários impedem o acesso à internet, pois ela é fonte inegável de informação.

Com o atual estágio da globalização, é evidente o papel que a informação tem. Informação essa que pode ter diferentes faces. Até mesmo um perfil em rede social tem valor econômico (QUANTO, 2016). Não é possível mais imaginar um mundo em que não exista a internet. Mais do que facilidades ao cotidiano, está pode proporcionar conhecimento, bem-estar, entretenimento, interações entre pessoas dentre outros benefícios.

\section{O INTERNET.ORG COMO UMA PRÁTICA DE DIFUSÃO DE ACESSO}

O Internet.org é uma iniciativa do Facebook que pretende dar acesso à Internet a toda população mundial de forma gratuita. Segundo Mark Zuckerberg - CEO do Facebook “Conectividade não pode ser um privilégio só dos mais ricos e poderosos. Ela deve se algo que todos possam compartilhar e ser uma oportunidade para qualquer um"3 (Tradução nossa) (ALL YOU NEED, 2016). A ideia é a possibilidade de dar acesso a informações básicas, sobre notícias, saúde, emprego, educação, clima, informações locais sem qualquer a necessidade de contratação onerosa de um pacote de dados de um provedor - o que é denominado de "free basic by Facebook". O objetivo, segundo o Facebook é difundir o acesso à internet, considerado um bem essencial, a todos, principalmente àqueles que não possuem condições financeiras para contratar um pacote de dados ${ }^{4}$.

Segundo informações do site Internet.org aproximadamente $85 \%$ do território mundial tem cobertura de dados fornecidos por provedores de telefonia móvel, assim o Facebook realizou parceira com algumas dessas operadoras de modo a fornecer, gratuitamente à população, o 'free basic'. Atualmente o serviço já está disponível em 37 países, espalhados pela África, Ásia e América Latina, dessa já fazem parte a Bolívia, Colômbia, Guatemala, México, Panamá e Peru.

Em seu site - Internet.org - o Facebook explica que caso uma operadora de telefone queira ser parceira nesse projeto ela terá vantagens. Informa ser um programa que torna a empresa sustentável, cumpridora de sua função social. Informa ainda que, durante algum tempo o Facebook irá auxiliá-los no custo desses novos usuários. A proposta é que, ao se manter uma campanha sobre a necessidade e facilidade que a Internet pode trazer à vida das pessoas, faz

\footnotetext{
${ }^{3}$ Connectivity can't just be a privilege for some of the rich and powerful. It needs to be something that everyone shares and an opportunity for everyone.

${ }^{4}$ Informações retiradas do site https://info.internet.org/en/
} 
com que esses novos usuários se interessem mais sobre o acesso à Internet e que, através de pesquisas ${ }^{5}$, sabe-se que após 30 dias de uso do "free basic", parte dos usuários estão dispostos a adquirirem um pacote de dados pagos.

A outra frente de acesso à Internet proposta pelo facebook se dá através da "connectivity lab". Nesse caso a proposta é levar Internet aos cantos mais remotos do mundo, onde não são providos por acesso à Internet móvel, através de uso de satélites, aviões, laser, entre outras tecnologias.

Outra forma de acesso se dá pelo "express wi-fi", neste caso o projeto visa realizar parcerias com empreendedores locais e provedores de acesso. Esse projeto já está sendo efetivado na Índia. O Facebook, neste caso, oferece software aos empreendedores locais que disponibilizarem o "express wi-fi" de modo a estabelecer uma melhor interconectividade entre os moradores locais, permitindo a exploração de informações.

Cabe ressaltar que o acesso à Internet disponibilizado pelo Internet.org não é ilimitado, assim, os usuários só terão acesso às páginas e aplicações dos parceiros do Facebook que se cadastraram para o uso do "free basic". Desta feita, o que o "free basic" faz é dar acesso à plataforma do Facebook e, através dela, os usuários terão acesso aos aplicativos e informações dos parceiros cadastrados.

O grande risco do "free basic" que vem sendo discutido mundo a fora diz respeito a uma possível violação do princípio da neutralidade da rede, hoje positivado no ordenamento jurídico brasileiro através do inciso IV, do artigo $3^{\circ}$ da lei 12.965 de 2014 (marco civil da internet). Esse princípio determina que o tráfego de dados deve se dar de forma igualitária, não podendo haver interferência na velocidade de transmissão de dados, nem restrição de acesso a esses dados. Segundo Silvia Melchior a neutralidade pode ser definida como:

[...] tratamento isonômico dado aos pacotes de dados que transitam na rede mundial de Internet (doravante Internet) e na infraestrutura de suporte, de forma que referidos dados sejam tratados de forma isonômica, independentemente do seu conteúdo, da sua origem ou destino, da aplicação ou serviço acessado, tecnologia e padrões técnicos envolvidos. (MELCHIOR, 2014, p. 101)

O marco civil da internet trata o princípio da neutralidade da rede de forma específica no artigo $9^{\circ}$ (BRASIL, 2014). Define que os provedores responsáveis pela transmissão, roteamento ou comutação de dados devem tratar os pacotes de dados de forma isonômica, de modo a não existir distinção em razão de conteúdo, origem e destino, serviço, terminal ou

\footnotetext{
${ }^{5}$ Informação retirada do próprio sítio do Internet.org - https://info.internet.org/en/
} 
aplicação. Pode-se perceber por essa definição que o objetivo primeiro desse princípio é assegurar a liberdade no âmbito da Internet de modo que o usuário não tenha limitações na busca de informações, seja em razão de filtros postos por provedores ou de uma maior disponibilidade de informações daqueles que pagaram ao provedor de transmissão de dados de modo que suas informações sejam acessíveis de forma mais rápida. Desta feita, será o usuário quem irá definir quais provedores de aplicações são de seu interesse e não o provedor de transmissão de dados. Essas premissas são capazes também de proteger a concorrência e inovação no mercado de aplicações na Internet, de modo que, não só os provedores de conteúdo mais ricos terão a possibilidade de tornar disponível suas aplicações, mas qualquer um, uma vez que será o usuário que irá escolher qual aplicação deseja usar.

O Facebook vem tentando uma parceria com o governo federal para a implementação do Internet.org no Brasil e isso vem gerando polêmica e discussão entre os acadêmicos da área. O Ministério Público Federal (2015), recentemente, emitiu uma nota técnica sobre a temática se posicionando de modo contrário a implementação do projeto. Segundo o Mistério Público Federal a iniciativa do Facebook não dá efetivamente acesso à internet, mas apenas a uma plataforma de parceiros do Facebook de modo gratuito por certo tempo. Informa ainda o Ministério Público Federal que a iniciativa não é sem fins lucrativos como faz crer o domínio de primeiro nível “.org”. O acesso às aplicações parceiras pode ser até gratuito, mas o objetivo do Facebook (e essa é umas das contrapartidas oferecidas por ele) é educar esses novos usuários sobre a natureza fundamental do acesso à Internet e incentivá-los a adquirirem um pacote de dados. Assim é que essa proposta parece uma "amostra grátis" de Internet com o objetivo de em um futuro próximo fazer com que esse consumidor adquira um pacote de dados do parceiro do Facebook.

Segundo o Mistério Público Federal as limitações de acesso não se restringem às parcerias firmadas com o Facebook. Também ocorrem restrição no tráfego de dados, não sendo carregados imagens maiores que 1Megabyte, vídeos e aplicações em java. Isso, por si só, seria uma violação ao princípio da neutralidade da rede por fazer uso de discriminação de tráfego de dados. Assim é que as camadas mais pobres da população que farão uso do "free basic" não terão acesso àquilo que o Facebook julgar como tráfego excessivo.

Outra preocupação esboçada pelo Ministério Público Federal é com o uso de dados dos usuários do "free basic" e seu consentimento informado para uso desses dados. O software usado pelo "free basic" é inseguro e permite, sem que o usuário saiba, a coleta de dados pessoais. Assim, como sabe-se que o Facebook é remunerado através de publicidade, isso poderia ser um facilitador para os seus parceiros no Internet.org para a publicidade. Portanto, 
após o tratamento de dados - que os usuários nem se quer sabem que estão sendo coletados - a publicidade desses parceiros estaria direcionada de forma mais fácil aos grupos de interesse.

Informa ainda o Ministério Público Federal que a difusão de acesso à Internet no Brasil deve ser de responsabilidade do Governo e não de uma empresa privada que tem o objetivo de dominação de mercado. O marco civil deixa claro essa necessidade de difusão da Internet e já existem diversas ações governamentais nesse sentido:

\begin{abstract}
Conforme noticiado no sítio da Telebrás, a empresa de economia mista vinculado ao Ministério das Comunicações tem previsão de lançamento do satélite SGDC-1 (Sistema Geoestacionário de Defesa e de Comunicações estratégicas) em 2016 que tem como principal foco a transmissão de banda larga para todo o território brasileiro. Tal acesso atenderá populações remotas e será gerenciado pelo Plano Nacional de Banda Larga do Governo Brasileiro, sem explorar interesses comerciais. Além do projeto estratégico de lançamento desse satélite, a empresa Telebrás já prepara mais dois outros projetos voltados para a universalização da banda larga no Brasil: O cabo Submarino Brasil-Europa e a Expansão da Rede de Fibra Ótica de longa distância. Ademais, cabe ressaltar ações como o Projeto Amazônia Conectada, gerenciada pelo Mistério da Defesa, que prevê a instalação de cabos subfluviais nos rios amazônicos para atendimento às comunidades locais. (MINISTÉRIO PÚBLICO FEDERAL, 2015)
\end{abstract}

Assim é que, para se evitar um domínio de mercador e uma possível limitação da liberdade dos usuários através do "free basic", a implementação desse tipo de empreendimento merece uma cautelosa avaliação. Em jogo podem estar uma série de restrições tais como: violações às boas práticas concorrenciais, uma possível dominação de mercado, a possibilidade de caracterização de venda casada, uma possível violação do princípio da neutralidade da rede, uso abusivo de dados dos consumidores e o consequente uso desses para a realização de publicidade agressiva, o acesso restritivo a informações e o possível controle das mesmas.

\title{
5 CONSIDERAÇÕES FINAIS
}

Como se viu a Internet deve ser considerada um bem essencial e, portanto, o seu acesso deve ser visto como um direito fundamental, mormente em se considerando que nela se difunde o conhecimento e a cultura. Nesse viés deve ser oportunizado o seu acesso a todos e sua promoção deve estar a cargo não só do Estado, mas em uma perspectiva de eficácia horizontal dos direitos fundamentais, também pelos privados.

Assim é que a prática oportunizada pelo Facebook através do Internet.org parece atender a essa premissa. Contudo, como se viu, há que se interpretar de maneira criteriosa esse empreendimento de modo que atenda aos requisitos legais exigidos por lei. 
Uma prática de acesso à Internet não pode se dar com o objetivo de dominação de mercado. Aparentemente, quando o Facebook oportuniza um acesso restrito a Internet através da sua plataforma e transparece ao consumidor que está fornecendo irrestrito acesso à rede mundial de computadores comete prática abusiva - propaganda enganosa - e viola a norma de proteção ao consumidor.

Outra ilegalidade que se vislumbra é a violação do princípio da neutralidade da rede, uma vez que limita a transmissão de dados que julgar excessivos. Desta feita, mais uma vez o consumidor é levado a crer que o acesso é irrestrito, mas será impedido de acessar as informações julgadas como de tráfego excessivo.

Outros problemas são apresentados no que se refere ao direito da privacidade do usuário, uma vez que a plataforma não garante a segurança dos dados pessoais dos usuários em uso na mesma. Desta feita, oportuniza-se a utilização indevida de dados pessoais sem o necessário consentimento informado dos usuários para uso desses dados, o que gera uma violação ao direito de privacidade e oportuniza, mais uma vez, uma prática abusiva por parte do Facebook. Explica-se, utilizando-se do tratamento não autorizado desses dados o Facebook pode oferecer aos seus parceiros no "free basic" a oportunidade de publicidade agressiva, uma vez que será possível determinar com uma maior precisão o público alvo desses produtos, inundando esses consumidores como uma publicidade assertiva e quase irrecusável.

O que ainda pode-se ser vislumbrado é a possibilidade de domínio de opinião dos usuários, na medida em que as informações podem ser manipuladas sem que os usuários saibam disso. Em uma Internet livre, sem a imposição de filtros pelos provedores, a informação é buscada de forma exclusiva pelo usuário. Sabe-se que essa ferramenta, o tratamento das informações, é uma forma de controle e submissão em Estados totalitários. Em Estados de Direito Democráticos, como o Brasil, esse tratamento pode ser visto como uma forma de dominação de mercado. Na medida em que o Facebook só oportunizará informações de seus parceiros, e esses, como se sabe são escolhidos por terem filosofia semelhante ao Facebook. Assim é que nesse viés, ao invés de uma prática de difusão de acesso ao bem essencial, o que se objetiva, aparentemente, é uma dominação de mercado e uma possível doutrinação dos usuários para a filosofia Facebook.

\section{REFERÊNCIAS}

ALL YOU NEED to know about internet.org,net neutrality and Facebook profile picture row.

In Today. 29 Set. 2015. Disponível em: 
<http://indiatoday.intoday.in/story/allyouneedtoknowaboutinternetorgnetneutralityandfaceboo kprofilepicturerow/1/485496.html> Acesso em: 02 mar. 2016

BITTAR, Carlos Alberto. Direito de Autor. $4^{\text {a }}$ ed. Rio de Janeiro: Editora Forense Universitária, 2003.

BONA VIDES, Paulo. Curso de Direito Constitucional. 31ª Ed. São Paulo: Malheiros, 2016

BRASIL. CONSTITUIÇÃO DA REPÚBLICA FEDERATIVA DO BRASIL DE 1988.

BRASIL. LEI No 10.406, DE 10 DE JANEIRO DE 2002. Institui o Código Civil. Diário Oficial da União. Brasília, 10 Jan. 2002.

BRASIL. LEI N 12.965, DE 23 ABRIL DE 2014. Estabelece princípios, garantias, direitos e deveres para o uso da Internet no Brasil. Diário Oficial da União. Brasília, 24 ABR. 2014.

BRASIL. LEI No 9.610, DE 19 DE FEVEREIRO DE 1998. Altera, atualiza e consolida a legislação sobre direitos autorais e dá outras providências. 19 de fev. de 1998

CORTE ALEMÃ julga internet como serviço essencial. Mundo Positivo. 25 jan. 2013.

Disponível em: <http://www.mundopositivo.com.br/noticias/brasil/20138626corte_alema_julga_internet_como_servico_essencial.html> Acesso em: 25 jan. 2015.

DIREITOS e Princípios da Internet. ONU. Disponível em <http://internetrightsandprinciples.org/pdf/10IRP_Portuguese.pdf>. Acesso em 14 mar. 2016

DOMÍNIO Público. Disponível em <www.dominiopublico.org.br>. Acesso em 14 mar. 2016

FERNADES. Bernardo Gonçalves. Curso de Direito Constitucional. $6^{\text {a }}$ Ed. Salvador: Editora JusPodivm, 2014.

GOULART, Guilherme Damásio. O Impacto das Novas Tecnologias nos Direitos Humanos e Fundamentais: O Acesso à Internet e a Liberdade de Expressão. Disponível em: http://papers.ssrn.com/sol3/papers.cfm?abstract_id=2156402; Acesso em 14 mar. 2016. 
LESSIG, Lawrence. Cultura livre: Como a Grande Mídia Usa a Tecnologia e a Lei Para Bloquear a Cultura e Controlar a Criatividade. São Paulo: Trama, 2005.

LÉVY, Pierre. Cibercultura. 1. ed. São Paulo: Editora 34, 1999.

MELCHIOR, Silvia Regina Barbuy. Neutralidade no direito brasileiro. In: MASSO, Fabiano Del. ABRUSIO, Juliana. FLORÊNCIO FILHO, Marco Aurélio. (Coords.) Marco Civil da internet: Lei 12.965/2014. São Paulo: Revista dos Tribunais, 2014.

MINISTÉRIO PÚBLICO FEDERAL. nota técnica MPF. Disponível em $<$ http://noticias.pgr.mpf.mp.br/noticias/noticias-dosite/copy_of_pdfs/NOTA_TECNICA_No02_2015_DA\%202a\%20E\%203a\%20CAMARA\%2 0DE\%20COORDENACaO\%20E\%20REVISaO_3.pdf/view>Acesso em 02 dez. 2015.

PINHEIRO, Patrícia Peck. Direito Digital. 3 ed. São Paulo: Saraiva, 2010.

POLI, Leonardo Macedo. Direito Autoral: parte geral. Belo Horizonte: Del Rey, 2008.

VIEGAS, Cláudia Mara de Almeida Rabelo; POLI, Leonardo Macedo. O Direito Autoral no Ciberespaço: A utilização autorizada e não autorizada de obras alheias. In: BRAGA NETTO, Felipe Peixoto; SILVA, Michael César. (Orgs.) Direito Privado e Contemporaneidade: Desafios e perspectivas do direito privado no século XXI. Belo Horizonte: D’Plácido, 2014.

QUANTO vale seu perfil no Facebook? Ferramenta de pesquisadores espanhois responde à pergunta. BBC BRASIL. Disponível em <http://www.bbc.com/portuguese/noticias/2015/11/151120_tecnologia_facebook_receita_perf il_lgb>. Acesso em 14 mar. 2016

REUTERS. Mais da metade da população mundial não tem acesso à internet, diz relatório da ONU. Tecnologia, 2015. Disponível em:

<http://oglobo.globo.com/sociedade/tecnologia/mais-da-metade-da-populacao-mundial-naotem-acesso-internet-diz-relatorio-da-onu-17557878>. Acesso em 14 mar. 2016 
ROSENAU, James N.; CZEMPIEL, Ernst-Otto. Governança sem governo: ordem e

transformação na política mundial. Brasília: Ed. Unb e São Paulo: Imprensa Oficial do Estado, 2000. 